\title{
História da educação da população negra: o estado da arte sobre educação e relações étnico-raciais (2003-2014)
}

\section{History of education of the black population: The state of art on education and ethnic-racial relations (2003-2014)}

\author{
Marcelo Pagliosa Carvalho*
}

\begin{abstract}
RESUMO
Este artigo traz resultados da Pesquisa "Educação e Relações Étnico-Raciais: o Estado da Arte", mais especificamente da Categoria "História da Educação da População Negra". Foram selecionados e analisados 31 artigos publicados em periódicos brasileiros da área da educação (2003-2014). Para facilitar o entendimento do conjunto dos artigos, acabamos por dividi-los em subcategorias que agrupassem temáticas em comum. Procurou-se construir um breve relato sobre os trabalhos catalogados e investigados, os dados estatísticos, as temáticas em destaque, os possíveis temas emergentes, as lacunas verificadas, os resultados comuns apontados nas pesquisas, as metodologias e os referenciais teóricos mais utilizados. Verificou-se uma diversidade temática nos artigos, constatada na abrangência das sete subcategorias recortadas. A temática mais trabalhada foi sobre os processos de inserção/exclusão da população negra na escolarização formal ou não-formal. Constatou-se que a contribuição científica estudada no conjunto dos artigos é de extrema importância, sobretudo ao visualizarmos a dificuldade na implementação da Lei $n^{\circ} 10.639 / 2003$ nos currículos escolares brasileiros da educação básica e de ações sobre as Histórias e as Culturas Africanas e Afro-Brasileiras no ensino superior.
\end{abstract}

Palavras-chave: História da Educação da População Negra. História da Educação. História e Cultura Africana e Afro-Brasileira.

* Universidade Federal do Maranhão. São Luís, Maranhão, Brasil. Av. dos Portugueses, n ${ }^{\circ}$ 1966. Bacanga. CEP: 65080-805. E-mail: marcelo.pagliosa@yahoo.com.br. ORCID: https://orcid. org/0000-0002-2498-525X 


\begin{abstract}
This article presents results from the Research "Education and Ethnic-Racial Relations: The State of Art", more specifically from the "History of Education of the Black Population" category. We selected and analyzed 31 articles published in Brazilian journals in the area of education (2003-2014). To facilitate the understanding of all articles, we ended up dividing them into subcategories that grouped common themes. We attempted to construct a brief report on the cataloged and investigated works, the statistical data, the topics in focus, the possible emergent themes, the gaps verified, the common results pointed out in the researches, the methodologies and the theoretical references most used. There was a thematic diversity in the articles, verified in the scope of the seven subcategories cut. The most worked on was the processes of insertion / exclusion of the black population in formal or nonformal schooling. It was verified that the scientific contribution studied in the articles as a whole is extremely important, especially when we see the difficulty in the implementation of Law 10.639/ 2003 in the Brazilian school curriculums of basic education and actions on the African and Afro-Brazilian Histories and Cultures in higher education.
\end{abstract}

Keywords: History of Education of the Black Population. History of Education. African and Afro-Brazilian History and Culture.

\title{
Introdução
}

Este artigo tem como foco o desenvolvimento da Categoria "História da Educação da População Negra" da Pesquisa "Educação e Relações Étnico-Raciais: o Estado da Arte" - Universidade Federal do Paraná/Universidade Federal do Maranhão/Universidade Federal de Minas Gerais/Secretaria de Educação Continuada, Alfabetização, Diversidade e Inclusão -Ministério da Educação (UFPR/UFMA/UFMG/SECADI-MEC), surgida a partir da proposição do Grupo de Trabalho em Educação e Relações Étnico-Raciais (GT 21) da Associação Nacional de Pós-Graduação e Pesquisa em Educação (ANPED). Foram selecionados e analisados artigos sobre a temática de periódicos da área da educação publicados entre 2003-2014. O objetivo da Pesquisa é analisar as repercussões da implantação/implementação da Lei ${ }^{\circ}$ 10.63/2003, que obriga a inclusão das Histórias e Culturas Africanas e Afro-Brasileiras nos currículos escolares, na produção científica brasileira. Ou, por outras palavras, como essa produção científica perscrutou a temática após a aprovação da referida Lei. 
Sem sombra de dúvidas, as políticas públicas voltadas à população negra brasileira ganham maior apoio governamental no interregno 2003-2014. Foram muitas as conquistas relativas às reivindicações históricas do movimento negro nesse momento: a criação da Secretaria Especial de Promoção da Igualdade Racial (Seppir) ${ }^{1}$; a promulgação da Lei ${ }^{\circ}$ 10.639/2003; a instituição das Diretrizes Curriculares Nacionais para a Educação das Relações Étnico-Raciais e para o Ensino de História e Cultura Afro-Brasileira e Africana (2004) e, em decorrência, do Plano Nacional de Implementação das Diretrizes Curriculares Nacionais para a Educação das Relações Étnico-Raciais e para o Ensino de História e Cultura Afro-Brasileira e Africana (2009); a aprovação do Estatuto da Igualdade Racial (2010); a implementação de políticas de ações afirmativas na modalidade cotas nas universidades públicas brasileiras; e a aprovação, de maneira unânime (2012), da constitucionalidade das ações afirmativas pelo Supremo Tribunal Federal (STF).

A construção e o estímulo de leis pelo Estado brasileiro no período, visando incluir a população negra brasileira a direitos antes alijados, marcaram uma mudança de rota histórica e necessária para a adoção de políticas antirracistas, sobretudo na área educacional. Tais políticas objetivavam a superação das desigualdades étnico-raciais ainda persistentes no país.

Neste texto estudaremos os 31 artigos que foram agrupados na Categoria "História da Educação da População Negra". Para tanto, foram criadas sete subcategorias que aglutinaram temáticas similares. Inicialmente será realizado um breve escrutínio sobre os números gerais dos artigos. Em seguida serão estudados os artigos englobados em suas respectivas subcategorias. Procuraremos verificar as temáticas em destaque, os possíveis temas emergentes, as lacunas verificadas, os resultados comuns apontados nas pesquisas, as metodologias e os referenciais teóricos mais utilizados. E, por fim, as conclusões gerais a que chegamos ao analisarmos os trabalhos em seu conjunto. Boa leitura!

\section{Os dados estatísticos da Categoria}

Verificou-se um importante crescimento de publicações na Categoria no período estudado (2003-2014). Enquanto nos primeiros seis anos (2003-2008)

1 A Seppir, que tinha status de Ministério, teve a nomenclatura posteriormente modificada para Secretaria de Políticas de Promoção da Igualdade Racial. Foi anexada, em meados de 2015, ao novo Ministério da Igualdade Racial, das Mulheres e dos Direitos Humanos. A então Ministra da Igualdade Racial, Nilma Lino Gomes, após amplos debates internos no governo, foi nomeada como ministra dessa nova pasta. Porém, após a retirada do poder da presidente eleita Dilma Roussef, esse Ministério foi abolido. 
foram encontrados apenas 3 trabalhos, nos últimos seis anos (2009-2014) catalogamos 28 artigos. Ou seja, com base nesses números, pode-se afirmar que a História da Educação da População Negra vem ganhando cada vez mais espaço nas revistas brasileiras (Tabela 1).

TABELA 1 - DISTRIBUIÇÃO TEMPORAL DOS 31 ARTIGOS DA CATEGORIA HISTÓRIA DA EDUCAÇÃO DA POPULAÇÃO NEGRA

\begin{tabular}{|c|c|}
\hline ANO & $\mathbf{N}^{\mathbf{0}}$ de artigos \\
\hline 2003 & 0 \\
\hline 2004 & 0 \\
\hline 2005 & 1 \\
\hline 2006 & 0 \\
\hline 2007 & 0 \\
\hline 2008 & 2 \\
\hline 2009 & 5 \\
\hline 2010 & 6 \\
\hline 2011 & 6 \\
\hline 2012 & 1 \\
\hline 2013 & 9 \\
\hline 2014 & 1 \\
\hline TOTAL & $\mathbf{3 1}$ \\
\hline
\end{tabular}

FONTE: Pesquisa Educação e Relações Étnico-Raciais: O Estado da Arte, 2017.

No total, foram localizados artigos em 23 revistas diferentes. A Revista HISTEDBR On-line, publicação do Grupo de Estudos e Pesquisas "História, Sociedade e Educação no Brasil" - HISTEDBR da Faculdade de Educação da Unicamp, que tem por objetivo publicar artigos resultantes de pesquisa ou de reflexão acadêmica, estudos analíticos e resenhas na área de história da educação, foi a que publicou o maior número de trabalhos: 4 . Em outras cinco publicações encontramos 2 artigos publicados: Revista Brasileira de História da Educação, História da Educação, Movimento, Perspectiva e Revista ABP. Cabe salientar que as duas primeiras se dedicam à divulgação de estudos sobre História da Educação. A Revista Movimento é uma publicação da Escola de Educação Física, Fisioterapia e Dança da Universidade Federal do Rio Grande do Sul; a Revista Perspectiva, da Universidade Federal de Santa Catarina, tem como objetivo divulgar a produção acadêmica sobre educação; e a Revista ABPN é a publicação da Associação Brasileira de Pesquisadores(as) Negros(as) (Tabela 2). 
TABELA 2 -DISTRIBUIÇÃO POR REVISTAS DOS 31 ARTIGOS DA CATEGORIA HISTÓRIA DA EDUCAÇÃO DA POPULAÇÃO NEGRA

\begin{tabular}{|c|c|}
\hline REVISTAS & $\mathrm{N}^{0}$ DE PESQUISAS \\
\hline Revista Brasileira de História da Educação & 2 \\
\hline Educar em Revista & 1 \\
\hline Educação e Realidade & 1 \\
\hline Acolhendo a Alfabetização nos Países de Língua Portuguesa & 1 \\
\hline Comunicações & 1 \\
\hline Contemporaneidade e Educação & 1 \\
\hline Educativa & 1 \\
\hline REVISTA ACTA SCIENTIARUM & 1 \\
\hline História da Educação & 2 \\
\hline Movimento & 2 \\
\hline Perspectiva & 2 \\
\hline Poiésis - UNISUL & 1 \\
\hline Reflexão e Ação & 1 \\
\hline Revista $A B P N$ & 2 \\
\hline Revista de Educação Pública & 1 \\
\hline Revista Educação e Fronteiras On-line & 1 \\
\hline Educação em Revista & 1 \\
\hline Revista Educação em Questão & 1 \\
\hline Revista HISTEDBR On-line & 4 \\
\hline Revista Intermeio & 1 \\
\hline Revista Teias & 1 \\
\hline Temas em Educação (UFPB) & 1 \\
\hline Tempo e Argumento & 1 \\
\hline TOTAL & 31 \\
\hline
\end{tabular}

FONTE: Pesquisa Educação e Relações Étnico-Raciais: O Estado da Arte, 2017.

Campinas (6), Porto Alegre (4), Florianópolis e Rio de Janeiro (3 cada) são as cidades-sede das revistas que concentraram mais da metade dos artigos: 16 (Tabela 3). 
TABELA 3 - DISTRIBUIÇÃO DOS 31 ARTIGOS DA CATEGORIA HISTÓRIA DA EDUCAÇÃO DA POPULAÇÃO NEGRA POR CIDADES-SEDE DAS REVISTAS

\begin{tabular}{|c|c|}
\hline ESTADOS & $\mathbf{N}^{\mathbf{0}}$ DE ARTIGOS \\
\hline Campinas & 6 \\
\hline Porto Alegre & 4 \\
\hline Florianópolis & 3 \\
\hline Rio de Janeiro & 3 \\
\hline Belo Horizonte & 1 \\
\hline Campo Grande & 1 \\
\hline Cuiabá & 1 \\
\hline Curitiba & 1 \\
\hline Dourados & 1 \\
\hline Goiânia & 1 \\
\hline João Pessoa & 1 \\
\hline Maringá & 1 \\
\hline Natal & 1 \\
\hline Pelotas & 1 \\
\hline Piracicaba & 1 \\
\hline Salvador & 1 \\
\hline São Paulo & 1 \\
\hline Santa Cruz do Sul & 1 \\
\hline Tubarão & 1 \\
\hline Total & $\mathbf{3 1}$ \\
\hline
\end{tabular}

FONTE: Pesquisa Educação e Relações Étnico-Raciais: O Estado da Arte, 2017.

No que concerne à região brasileira em que se situam as revistas, as regiões Sudeste e Sul tiveram 12 artigos publicados cada uma; a Região Centro-Oeste contribuiu com 4 artigos e a Região Nordeste com 3. Não catalogamos artigos em revistas publicadas na Região Norte (Tabela 4).

TABELA 4 - DISTRIBUIÇÃO DOS 31 ARTIGOS DA CATEGORIA HISTÓRIA DA EDUCAÇÃO DA POPULAÇÃO NEGRA POR REGIÕES DAS REVISTAS

\begin{tabular}{|c|c|}
\hline REGIÕES & N $^{\mathbf{0}}$ DE ARTIGOS \\
\hline Sudeste & 12 \\
\hline Sul & 12 \\
\hline Centro-Oeste & 4 \\
\hline Nordeste & 3 \\
\hline Norte & 0 \\
\hline Total & $\mathbf{3 1}$ \\
\hline
\end{tabular}

FONTE: Pesquisa Educação e Relações Étnico-Raciais: O Estado da Arte, 2017. 
Quanto à distribuição por gênero, catalogamos 23 autoras e 16 autores. É mister salientar que o número de artigos é menor em relação ao número de pesquisadores(as) porque há a ocorrência de trabalhos com mais de um(a) autor(a) (Tabela 5).

TABELA 5 - DISTRIBUIÇÃO DOS 31 ARTIGOS DA CATEGORIA HISTÓRIA DA EDUCAÇÃO DA POPULAÇÃO NEGRA POR GÊNERO

\begin{tabular}{|c|c|}
\hline FEMININO & MASCULINO \\
\hline 23 & 16 \\
\hline
\end{tabular}

FONTE: Pesquisa Educação e Relações Étnico-Raciais: O Estado da Arte, 2017.

Em relação à periodização histórica, o período republicano se destaca com a maioria dos trabalhos: 18 (Tabela 6).

\section{TABELA 6 - DISTRIBUIÇÃO POR PERÍODO HISTÓRICO ESTUDADO PELOS 31 ARTIGOS DA CATEGORIA HISTÓRIA DA EDUCAÇÃO DA PO- PULAÇÃO NEGRA}

\begin{tabular}{|c|c|}
\hline PERÍODO HISTÓRICO & $\mathbf{N}^{\mathbf{0}}$ DE PESQUISAS \\
\hline Colônia & 1 \\
\hline Império & 5 \\
\hline República & 18 \\
\hline Império e República & 7 \\
\hline Total & $\mathbf{3 1}$ \\
\hline
\end{tabular}

FONTE: Pesquisa Educação e Relações Étnico-Raciais: O Estado da Arte, 2017.

Agrupamos os artigos por similaridades temáticas, perfazendo um total de sete subcategorias levantadas. A subcategoria "Educação das crianças e jovens negros(as)" foi a que abarcou o maior número: 10 pesquisas. Em seguida aparece "Iconografia e representações dos(as) negros(as) nos livros didáticos" (5 trabalhos). "Diálogos e reflexões sobre África" abrangeu 4 pesquisas, mesmo número de artigos da subcategoria "Outros", que aglutinou pesquisas que não apresentaram similaridades temáticas com outras investigações. "Lutas coletivas da população negra e educação" e "A História das Mulheres Negras e Educação" apresentaram três artigos cada. Por fim, a subcategoria "Docentes e/ou intelectuais negros(as): trajetórias profissionais e de vida" abrangeu 2 trabalhos. 


\section{As subcategorias levantadas e a análise dos trabalhos selecionados}

A primeira subcategoria, "Educação das crianças e jovens negros(as)", abarcou dez artigos. Silva e Silva (2005) discutiram as desigualdades educacionais vividas pelos afrodescendentes, como uma das consequências do projeto de educação elaborado no processo de abolição da escravatura no Brasil. Constatou-se que as iniciativas desenvolvidas pelas classes dominantes para a educação da população negra procuraram conservá-la/abarcá-la como mão de obra para a produção e submissão. As autoras (2005) afirmam que a história da educação no Brasil e, em especial, a inserção dos negros na educação brasileira constitui-se em uma trajetória permeada por conflitos, contradições, preconceito e exclusão. Apontam que as organizações negras têm combatido esse déficit, por meio de estratégias e de diversos projetos pedagógicos, que impulsionam políticas públicas reparativas.

Luz (2013) debateu as práticas de escolarização e alfabetização entre a população negra no contexto do Brasil oitocentista, mais especificamente em Recife, com foco na implementação oficial das aulas de primeiras letras para mestres e aprendizes de ofícios da Sociedade dos Artistas Mecânicos e Liberais de Pernambuco, observando as repercussões sociais e étnicas dessa ação educativa. A conclusão realça que essa Sociedade foi umas das entidades coletivas que se constituiu como espaço privilegiado de acolhimento e proteção, ou mesmo instâncias de reivindicação por demandas específicas, com as quais a população negra contou. $\mathrm{O}$ artigo mostra ainda a importância de um número maior de estudos sobre a participação ativa dos negros no processo de alfabetização realizado no país e os seus aportes para a difusão de tal conhecimento e a consolidação do próprio espaço escolar.

Discutir as políticas eugênicas e sanitaristas das primeiras décadas do séc. XX e sua apropriação pela escola, na formação do cidadão nacional, tendo como recorte o Paraná foi o objetivo de Renk (2014). Tais políticas tinham o seguinte pressuposto: como a maioria da população desse estado era constituída de população branca, não havia razão para branquear a população, mas "melhorá-la" por meio da higiene e da educação física. O Estado implementou políticas eugênicas com a intenção de regular e controlar a população. As práticas sociais da população cabocla, indígena e negra deveriam ser descartadas, com isso se moldaria os modos dos jovens e "branqueariam" as suas atitudes. Ou seja, as políticas oficiais apregoavam a moldagem do "cidadão nacional", por meio de extensos exames de saúde, psicológicos e fisiológicos aplicados nas escolas. As políticas de Estado, em suma, encontraram na escola um campo fértil às suas 
ações e as políticas higienistas contribuíram na busca pela homogeneização da população.

O artigo de Sá e Cruz (2008) expõe os resultados iniciais de um estudo acerca da influência do racismo europeu na instrução pública primária do Mato Grosso na transição do século XIX para o XX, analisando principalmente o discurso oficial e das elites letradas sobre a instrução pública primária. Procurou-se examinar o sistema simbólico que fundamentou a produção de uma instrução pública primária seletiva e discricionária em relação a negros, pardos e brancos pobres. Averiguou-se de que forma a instrução pública primária incorporou os conceitos raciais concernentes no projeto político das classes dominantes, definindo as concepções de povo e nação, e como elas interferiram no acesso e na permanência dos grupos excluídos economicamente no ambiente escolar.

Abreu (2011) discutiu a escolarização dos negros no início do período Republicano e analisou o alargamento da concepção de fontes em história da educação, com o objetivo de construir uma historiografia menos estereotipada. Enfatizou que a fonte é construída a partir do recorte realizado pelo historiador e que há certo padrão de invisibilidade dos negros na historiografia educacional. Ressaltou a problemática da insuficiência de abordagens históricas acerca das trajetórias educacionais da população negra no país.

Lorenz (2009) analisou a natureza e os efeitos da disciplina de Educação Física em relação às crianças menos-favorecidas do Brasil, primeiramente sob os preceitos de Higiene Escolar e, posteriormente, sob a perspectiva da Eugenia no interregno 1870-1930. Destaca as ideias raciais de Fernando de Azevedo sobre a Educação Física enquanto agente regenerador da "Raça Brasileira" e medida corretiva dos efeitos negativos da miscigenação.

Desvendar se as crianças negras livres que viviam em Cuiabá tinham acesso à escolarização no período de 1871-1890 constituiu-se no objetivo de Miranda e Sá (2011). Verificou-se um número significativo de negros na sociedade. Conquanto a educação fosse preconizada como ação primordial da administração pública, observou-se que grande parte da população infantil pobre, sendo ela branca ou negra, encontrava-se alijada da escola. Foi possível verificar, no entanto, que um expressivo número de crianças negras estudava nas escolas cuiabanas, apesar de as autoras ressaltarem que a educação não estava disponível para todos e que o preconceito se mostrava presente nas relações cotidianas escolares.

Examinou-se três artigos de Fonseca (2009a, 2009b e 2011). No primeiro, o autor (2009a) analisou o processo de estabelecimento da obrigatoriedade escolar, ocorrida em Minas Gerais (1835), enquanto elemento de mediação entre o perfil racial da população e a ideia de civilização que orientou o processo de construção da educação. Mostrou que o estabelecimento da obrigatoriedade da 
instrução elementar não passou de uma carta de intenções, pois houve baixo crescimento das matrículas nas escolas mineiras no período. Com isso, o autor afirma que a definição dessa obrigatoriedade escolar pode ser concebida enquanto a representação de um ideário civilizatório como metáfora de processo racializado, que apregoava o papel fundamental da educação no processo de controle da população. No segundo artigo, Fonseca (2009b) reuniu parte da bibliografia sobre os negros na historiografia educacional, destacando as principais características da produção realizada na área. Afirmou a necessidade de uma postura dos historiadores no sentido de integrar de forma plena a população negra à história da educação. Criticou autores que defendem a necessidade do surgimento de uma dimensão específica da historiografia para o trato dessa questão, que comumente seria denominada de "história da educação dos negros" e que ganham força a partir dos anos 1990. Apesar dessa produção, apontou que não houve impactos para que a temática racial fosse realmente levada em consideração pelas análises historiográficas. Para finalizar, no texto de 2011, procurou apresentar um conjunto de fontes documentais que permitem examinar os encaminhamentos em torno do movimento de vinculação entre a educação e a questão relativa à libertação dos escravos. A educação foi um tema com ampla ressonância durante o processo de abolição do trabalho escravo, sobretudo nos embates da promulgação da Lei do Ventre Livre (1871). O artigo destacou o livro Vítimas-algozes: quadros da escravidão, do escritor Joaquim Manoel de Macedo. Situou a obra nos debates acerca da abolição da escravatura e salientou a sua importância no que tange à educação das crianças escravas. Concluiu que a Lei isentou os senhores de escravos de uma educação das crianças em nível instrucional, porém determinou que aquelas que fossem entregues ao Estado fossem atendidas em processos de formação. Dados de 1871 a 1888 revelaram que o governo imperial realizou iniciativas para que a dimensão educacional definida pela lei fosse implementada, entretanto, os escravocratas procuraram reter as crianças abarcadas pela Lei do Ventre Livre como trabalhadores não remunerados até os vinte e um anos de idade.

A segunda subcategoria foi denominada "Lutas coletivas da população negra e educação" e abrangeu três artigos. Pereira (2010) analisou a confecção de estratégias educacionais por afrodescendentes implementadas por algumas organizações negras em Porto Alegre-RS entre os anos finais do séc. XIX até o ano de 2002. As particularidades, as diretrizes de organização e de reivindicações de cada uma das entidades são levantadas e estudadas no trabalho. A característica comum a todas elas foi a luta pela preservação da identidade e pelo estabelecimento de condições dignas de sobrevivência aos afrodescendentes. A educação foi o princípio básico das ações dessas organizações.

Salvadori (2013) examinou resultados preliminares de estudo sobre a história do Clube Beneficente, Cultural e Recreativo 28 de Setembro, funda- 
do em 1897 em Jundiaí, o mais antigo clube negro do Estado de São Paulo e um dos mais longevos do país. Apontou as mudanças pelas quais passou essa entidade ainda em atividade, que teve em seu início a presença marcante dos trabalhadores negros ferroviários. Identificou as nuances que se relacionam às trajetórias singulares dos sujeitos e às diferentes vontades das várias gerações de afrodescendentes, suas inserções no mercado de trabalho, nos processos educativos e nas lutas coletivas empreendidas. Por fim, destacou que os clubes negros inaugurados em diferentes momentos da história brasileira têm procurado realizar uma ação conjunta para serem reconhecidos como patrimônio histórico e cultural afro-brasileiro.

O objetivo de Marques (2013) foi estudar o protagonismo do negro no processo abolicionista cearense e na luta por liberdade, a partir do aspecto cultural, em especial das Irmandades do Rosário. As práticas culturais negras sofreram fortes cerceamentos na segunda metade do séc. XIX. Entretanto, as manifestações culturais advindas dos negros no Ceará resistiram e persistiram, como os congos, candomblés e maracatus. Apesar de ter sido a primeira província a abolir a escravidão, o estudo apontou que o processo abolicionista cearense promoveu certa invisibilidade do negro na história desse local.

Dois trabalhos foram dispostos na subcategoria 3 "Docentes e/ou intelectuais negros(as): trajetórias profissionais e de vida”. Müller (2010) apresentou dados sobre a origem racial de candidatos a concursos para professores no magistério público do Rio de Janeiro na Primeira República. Discutiu o processo de branqueamento do magistério com base nos debates acerca da pretensa inferioridade da população negra e averiguou as formas de classificação racial dos brasileiros na época. Para a autora (2010), a cor da pele, que é um atributo meramente biológico, assume um conteúdo cultural, social e moral em um imenso conjunto de qualificativos inferiorizantes, vitimando sobretudo a população negra. Como conclusão, há a consideração de que a exclusão dos negros nos cargos docentes elaborados no período estudado repercute inclusive nos dias atuais, em um cenário em que ainda é pequena a presença de professoras(es) negras(os) na educação brasileira.

Camara e Cockell (2011) historicizaram o livro A América Latina: males de origem (1905) de Manoel Bonfim (1868-1932), identificando suas contribuições teóricas e as análises sobre os fatores socioculturais que auxiliavam a explicar a sociedade brasileira no contexto do que se caracterizou como a Belle Époque tropical (1898-1914). Enfocou o combate analítico do escritor diante das defesas intelectuais que salvaguardavam a suposta inferioridade cultural, social e econômica dos latino-americanos; destacou as defesas de Bonfim de que os males que nos afligiam não eram consequências da composição étnica, climática ou de uma suposta inferioridade racial. Ressaltam que Manoel Bonfim 
se colocou como um árduo defensor da instrução como um elemento que poderia fornecer um desenvolvimento para as sociedades latino-americanas buscarem a democracia, o que colaborou para desmistificar as teorias darwinistas de seleção natural e de superioridade racial.

A subcategoria 4 "Diálogos e reflexões sobre África" abarcou quatro artigos. Pinto (2007) refletiu acerca das origens e das identidades que embasaram o que se entende atualmente por continente africano. Debateu que a procura pela interpretação da África deveria começar a partir do legado deixado pelo colonialismo e pela luta em prol do fortalecimento de uma efetiva soberania interna. Muitos governantes africanos enfrentam o problema de unificar nações que têm ligações culturais/religiosas diversas, com o complicador da formação arbitrária das fronteiras do Estado no período da dominação colonial. A consolidação dos Estados nacionais enfrentou duas frentes de ameaça: de um lado, as potências coloniais e, do outro, o fortalecimento do pan-africanismo que defendia a identidade transfronteiriça. Os líderes dos Estados nacionais no pós-independência tiveram que forjar um consenso em torno da formação e governança desses Estados. Concluiu citando que o entendimento da identidade africana não é uma tarefa fácil, pois trata-se de um continente fragmentado em inúmeras etnias que não encontraram a paz social, com os maiores índices de pobreza e subdesenvolvimento do planeta e com escassos recursos naturais.

Apresentar resultados de pesquisa sobre a música produzida em Angola (1950 a 1980) foi o objetivo principal de Alves (2013). A luta anticolonial possuiu valiosas características no cenário africano: denúncias escritas por intelectuais; a produção literária de protesto; diferentes e divergentes movimentos sociais e políticos de luta pela liberdade; greves; desobediência civil. Assinalou que a música popular angolana passou por diferentes fases no período, sendo que a música popular urbana auxiliou na construção de uma consciência nacionalista, contribuindo para a resistência anticolonial. Identificou as transformações no conteúdo das letras das canções durante a época perscrutada, que abordaram temas como cultura tradicional, resistência, luta anticolonial e a construção de um novo nacionalismo, proposto pelo governo socialista do Movimento Popular de Libertação de Angola (MPLA).

Domingos (2012) analisou a diversidade cultural e a alteridade na Costa Oriental africana, bem como as condições e consequências do encontro entre as culturas africana, asiática e europeia presentes em Moçambique. Destacou a importância de conceitos como o de cultura em movimento, novas formas de identidades plurais e apontou a necessidade de se reconciliar as sociedades com seus passados comuns, lançando as bases da solidariedade e da paz para o futuro, aceitando os desafios das relações serem baseadas no respeito pela diversidade cultural e pela valorização de uma humanidade universal. 
Foe (2013) examinou a relação entre Europa e África, debatendo como a condição pós-colonial manteve/mantém uma tensão entre duas diferentes compreensões dessa relação. Assinalou que afirmações como "A África não tem história" têm raízes profundas em interpretações de pensadores europeus que se perguntaram sobre o grau de humanidade do negro (Kant, Voltaire, Montesquieu etc.). Ressaltou que uma antiga questão ainda não foi resolvida: a da unidade negativa ou da polarização do mundo. Os filósofos da libertação não teriam encarado nitidamente a supressão dessa contradição fundamental pela desconexão, a saída do Império, a ruptura dos laços de servidão com o centro capitalista. Como resposta a isso, o autor destaca a importância de "retomada da iniciativa histórica" pela periferia, segundo a perspectiva de Aimé Césaire, Kwame Nkrumah, Marcien Towa e Samir Amin.

A quinta subcategoria foi denominada de "A História das Mulheres Negras e Educação" e teve três artigos selecionados. Almeida (2009) apreendeu a ausência de políticas públicas voltadas à escolarização e a relação com o sentimento de exclusão presente nas memórias de mulheres negras de Juiz de Fora-MG. Averiguou que a impossibilidade de prosseguimento dos estudos dessas mulheres constituía-se como parte da realidade da educação brasileira. As memórias negras dessas meninas atribuem significativa relevância com o fato de terem acessado os bancos escolares. Por fim, há o destaque de que o Fundo Nacional do Ensino Primário (FNPE), nos anos 1950, proporcionou o aumento da oferta de vagas e possibilitou o acesso da população negra feminina.

Almeida e Alves (2011) investigaram aspectos relativos à história da educação de mulheres negras com base na análise dos fragmentos de memória acerca da trajetória educacional de mulheres, sobretudo na cidade de Juiz de Fora-MG (1950-1970). Estudaram aspectos referentes à cultura escolar e à democratização da escola pública no Brasil e como as políticas públicas voltadas à escolarização interferiram nas histórias de vida das mulheres negras. Apreenderam que a impossibilidade de prosseguimento dos estudos vivenciada pelas mulheres negras de Juiz de Fora não fugia muito da realidade vivida no cenário educacional de exclusão brasileiro. $\mathrm{O}$ não acesso à escolarização aparece nas memórias negras numa posição de grande relevância. Até mesmo nos casos em que conseguiram acessar a escola, as mulheres negras não apagaram de suas memórias o registro dos desconfortos e das importantes ultrapassagens no esforço cotidiano de realização do desejo de estudar.

Araújo (2013) discutiu o papel que a mulher negra desempenhou no pós-Abolição. Destacou a necessidade de se realizar o corte de gênero nas análises da história da população negra brasileira e retratou o protagonismo das mulheres negras enquanto mantenedoras das tradições e responsáveis principais pela organização familiar. 
A sexta subcategoria "Iconografia e representações dos(as) negros(as) nos livros didáticos" abarcou cinco artigos. Analisar modalidades de uso da imagem irônica e satírica por meio de recorte étnico de charges e cartuns foi o objetivo de Souza (2013). Com o intuito de repensar as representações do negro nas práticas pedagógicas, partiu do pressuposto de que as charges podem ser apropriadas com o objetivo de denunciar ou de silenciar, invisibilizar e estereotipar/discriminar. Afirmou a importância do uso didático das charges e dos cartuns, na medida em que podem provocar o aspecto risível, ridicularizando determinadas artimanhas do poder com o recurso do exagero, do grotesco e da comicidade. São gêneros textuais que registram a representatividade do cotidiano social do afro-brasileiro, de práticas culturais excludentes no tocante ao respeito à população negra, que recriam situações sociais pelo viés satírico, que desvelam vivências ou situações de discriminação que, na práxis social, aparecem mascaradas.

O artigo de Abramowicz et al. (2011), em linhas gerais, propõe uma iconografia da criança negra. Objetiva ressaltar a maneira pela qual a criança e sua infância foram retratadas no século XIX e início do século XX, sobretudo a criança negra. A análise foi consubstanciada em uma pesquisa iconográfica e teve como fonte alguns acervos históricos brasileiros. Foram utilizadas imagens fotográficas organizadas e examinadas levando em consideração as seguintes temáticas: gênero, raça e classe social. Procurou-se retratar as crianças enquanto protagonistas da história, pois, em geral, aparecem apenas como vestígios, invisíveis e ocultas. Observou-se que há raríssimas fotos de crianças catalogadas/dispostas para análise. Apesar dessa dificuldade para a realização da pesquisa, evidenciou-se a presença de crianças negras em retratos que contemplam cenas da vida cotidiana sem alusão à escravidão. As crianças negras são retratadas e reconhecidas referindo-se ao exotismo do trabalho escravo, em virtude disso, o olhar analítico procura desviar de uma determinada maneira hegemônica de representá-las no século XIX.

Arantes (2013) investigou imagens e representações de negros veiculadas nos livros escolares de leitura que circulavam nas escolas primárias pernambucanas no século XIX. Aferiu que os livros traziam os negros representados como inferiores, incivilizados e, mesmo quando eram considerados como heróis, como é o caso de Zumbi e Henrique Dias, a sua cor interferia no heroísmo. Esse quadro negativo delineado influenciou na formação intelectual das crianças e dos jovens, contribuindo para a manutenção de ideias discriminatórias.

Pina (2010) examinou como a nação brasileira foi retratada no manual de História do Brasil (1915) de Antônio Alexandre Borges dos Reis, utilizado no Ginásio da Bahia. Verificou-se que o autor, como outros escritores da época, era defensor de um caminho evolutivo do país em direção à "civilização", fortalecendo uma identidade nacional branca, cristã e liberal. Apesar disso, constatou que ele condenava a escravidão dos negros, apesar de justificá-la economicamente, 
e reconhecia o valor dos negros na construção do país, porém não salienta como uma ação decisiva no destino brasileiro. O patriotismo, o nacionalismo e a exaltação da identidade nacional foram disseminados no manual perscrutado.

Buscar compreender como foram apresentadas as raças humanas nos manuais escolares de Zoologia publicados na segunda metade do sec. XIX e no início do séc. XX foi o cerne do trabalho de Cavadas (2013). Afirmou que nos manuais de Zoologia portugueses o conceito de raça humana foi apresentado até 1919 , quando os primeiros programas republicanos o abandonam. A pretensa hierarquização dos seres humanos em escalas qualitativas e quantitativas mostrou-se presente em muitos trechos dos manuais, com afirmações que declaravam a raça caucasiana como superior e a negra como inferior. Em síntese, os autores desses manuais eram apologistas do determinismo biológico.

A subcategoria 7 "Outros Temas" abrangeu quatro artigos que não se encaixaram em nenhuma das anteriores. Boto (2010) analisou o discurso eugenista brasileiro nos anos de 1930, período em que houve um conjunto significativo de intelectuais e de políticos que discorreram sobre a temática da nacionalidade brasileira. Observou-se que as discussões políticas sobre a acepção de raça estiveram presentes, bem como as pretensas intenções de aprimorar a composição étnica do povo brasileiro, argumentação defensora do incentivo de imigrações europeias. $\mathrm{O}$ debate eugenista fez-se presente em discursos elitistas da época. A autora (2010) salientou que a mesma década de 1930, marcada pelo estabelecimento de direitos sociais, das conquistas trabalhistas e pelo caráter progressista disposto na Constituição Federal de 1934 para a educação, foi também marcada pelas ideias eugenistas.

Cressoni (2010) verificou a contribuição dos sermões do jesuíta Antônio Vieira para a manutenção da escravidão africana na América portuguesa. Afirmou que esses sermões eram instrumentos pedagógicos a serviço dessa manutenção. Buscou compreender as razões de sua pregação aos negros trazidos da África e os desdobramentos desse processo. Observou que auxiliavam na possibilidade de conversão empreendida pelos membros da Companhia de Jesus no contato com os africanos escravizados. As argumentações e finalidades desse discurso eram resultantes de uma capacidade de visualizar somente a si próprio no outro, considerando tão-somente sua experiência social, impondo ao diferente sua forma de ser, implicando-lhe um aprendizado social divergente da sua realidade. Cressoni (2010) realizou uma interpretação diferente dos autores cuja linha de pensamento proclamava que o jesuíta teria atuado como um defensor dos negros, pregando inclusive a libertação desses escravizados. Destacou que nos sermões de Antônio Vieira fica nítida que a salvação do segundo cativeiro (inferno) importaria muito mais do que a continuidade do primeiro (engenho), pois este último seria passageiro. 
Abrahão e Soares (2009) examinaram a culpa atribuída a Barbosa, ex-goleiro da seleção brasileira, na Copa do Mundo de 1950, sob a perspectiva do debate sobre raça e racismo. Analisaram a presença do debate racial em textos acadêmicos que apontaram Barbosa como o algoz da derrota na final do torneio disputado no Brasil e que expressavam significados acerca das relações raciais na cultura brasileira. Discutiram as representações, a sobreposição de narrativas sobre o racismo, e conceitos como o mito da democracia racial e a mestiçagem.

Santos, Caprano e Lise (2010) estudaram os discursos de Mário Filho e suas considerações sobre a existência do racismo no futebol, que se tornou emblemático após a derrota da seleção brasileira de futebol na Copa do Mundo de 1950, na qual jogadores negros da seleção, em especial o goleiro Barbosa, foram alvos de racismo. Salientaram, porém, que não foi encontrado, nas notícias da época, nenhum indício que reiterasse o argumento racista em que se balizou Mário Filho. Dois jogadores são culpabilizados pela derrota, Barbosa e Bigode (negros), mas, de acordo com os/as autores/as (2010), não se estabelece qualquer tipo de preconceito racial, pois os demais negros que faziam parte da seleção atuaram de maneira satisfatória, segundo os periódicos pesquisados. $\mathrm{O}$ artigo cita a contradição dos discursos de Mário Filho presente nas duas primeiras edições de "O Negro no Futebol Brasileiro". A interpretação da segunda edição se configuraria como uma tradição inventada, pois os periódicos da época não traziam menções a essas situações de aumento do racismo.

\section{Considerações finais sobre os artigos}

Os artigos foram escritos por: orientandos(as) e orientadoras(es) em parceria; estudantes ou recém-egressos de cursos de pós-graduação; pesquisadoras(es) consolidados(as)/professores(as) universitários que produziram individualmente ou em companhia de outras(os). Em razão dessa variedade, as publicações foram também diversas: trabalhos frutos de pesquisas de pós-graduação em andamento; resultados de dissertações de mestrado ou de teses de doutoramento; artigos com amplitude maior, pois redigidos por investigadoras(es) experientes. A maior parte se dedicou a estudos de caso, mas houve a ocorrência de pesquisas com cunho histórico ou historiográfico que englobavam períodos ou territórios mais extensos e textos com abordagens epistemológicas.

A temática mais trabalhada foi sobre os processos de inserção/exclusão da população negra na escolarização formal ou não formal. As políticas eugenistas desenvolvidas pelos poderes públicos brasileiros é outro tema presente com força nessa Categoria. Destaque também aos trabalhos que procuraram realizar 
um estudo sobre como a iconografia representou a população negra nos livros didáticos. As reflexões sobre o continente africano, quer seja sobre aspectos estritamente educacionais, quer seja acerca das questões sociais, políticas ou econômicas, atestam a presença de a) pesquisadoras(es) africanos(as) que realizaram cursos de pós-graduação e/ou são docentes universitários(as) no Brasil e b) pesquisadores(as) e estudantes brasileiros que começaram a se dedicar aos estudos sobre o continente africano. Essa contribuição científica é de extrema importância, em especial quando visualizamos a dificuldade de implementação da Lei $n^{\circ} 10.639 / 2003$ (e de seus decorrentes planos) nos currículos escolares brasileiros da educação básica e do ensino superior.

Em linhas gerais, podemos sublinhar que o conjunto das pesquisas tem o mérito de discutir temas que foram/permanecem silenciados nas produções educacional e histórica brasileiras, talvez mais na primeira que na segunda. Observa-se uma disposição dos/as (não só, mas principalmente) pesquisadoras(es) negras(os) em resgatar essas histórias, essas memórias, essas lutas, essas trajetórias de vida silenciadas, ocultadas na ciência brasileira. Os negros sempre reivindicaram maiores espaços de poder, mais oportunidades sociais e educacionais, e isso se mostra em um processo crescente nos últimos anos, como bem demonstram os artigos. E isso é muito importante. É justiça a ser feita. São espaços democráticos que estão sendo reivindicados e criados, apesar de toda discriminação racial presente nesse país. Esse é certamente o discurso mais consolidado no conjunto dos trabalhos.

\section{REFERÊNCIAS}

ABRAHÃO, B. O. de L.; SOARES, A. J. O que o Brasileiro não esquece nem a tiro é o chamado Frango de Barbosa: questões sobre o racismo no futebol brasileiro. Revista Movimento, Porto Alegre, v. 15, n. 2, p. 13-31, abr./jun. 2009. Disponível em: <http:// www.seer.ufrgs.br/Movimento/article/viewFile/3033/5132>. Acesso em: 10 ago. 2016.

ABRAMOWICZ, A.; SILVEIRA, D. de B.; JOVINO, I. da S.; SIMIÃO, L. F. Imagens de crianças e infâncias: a criança na iconografia brasileira dos séculos XIX e XX. Revista Perspectiva, Florianópolis, v. 29, n. 1, p. 263-293, jan./jun. 2011. Disponível em: <https://periodicos.ufsc.br/index.php/perspectiva/article/viewFile/2175-795X.2011v29n1p263/19436>. Acesso em: 10 ago. 2016.

ABREU, D. C. L. de. A Escolarização dos negros e suas fontes de pesquisa. Revista HISTEDBR On-Line, Campinas, n. 42, p. 235-248, jan. 2011. Disponível em: <http:// www.histedbr.fe.unicamp.br/revista/edicoes/42/art15_42.pdf $>$. Acesso em: 10 ago. 2016. 
ALMEIDA, G. E. S. de; ALVES, C. M. C. Educação escolar de mulheres negras: interdições históricas. Revista Educação em Questão, Natal, v. 41, n. 27, p. 81-106, jul./dez. 2011. Disponível em: <https://periodicos.ufrn.br/educacaoemquestao/article/ viewFile/4003/3270>. Acesso em: 10 ago. 2016.

ALMEIDA, G. E. S. de; ALVES, C. M. C. História da educação escolar de mulheres negras: as políticas públicas que não vieram. InterMeio: Revista do Programa de Pós-Graduação em Educação, Campo Grande, v. 15, n. 30, p. 219-232, jul./dez. 2009. Disponível em: <http://docplayer.com.br/11760147-Historia-da-educacao-escolar-de-mulheres-negras-as-politicas-publicas-que-nao-vieram.html>. Acesso em: 10 ago. 2016.

ALVES, A. P. Angola: musicalidade, política e anticolonialismo (1950-1980). Revista Tempo e Argumento, Florianópolis, v. 5, n. 10, p. 373-396, jul./dez. 2013. Disponível em: <http://revistas.udesc.br/index.php/tempo/article/viewFile/2175180305102013373/2848>. Acesso em: 10 ago. 2016.

ARANTES, A. S. Representações de negros em livros escolares de leitura utilizados nas escolas primárias pernambucanas (1843-1897). Revista Brasileira de História da Educação, Campinas, v. 13, n. 2 (32), p. 73-99, maio/ago. 2013. Disponível em: $<$ http:// www.rbhe.sbhe.org.br/index.php/rbhe/article/view/370/pdf>. Acesso em: 10 ago. 2016.

ARAÚJO, A. S. A mulher negra no pós-abolição. Revista da ABPN, Rio de Janeiro, v. 5, n. 9, nov. 2012/fev. 2013, p. 22-36. Disponível em: http:/www.abpn.org.br/Revista/ index.php/edicoes/article/view/278/238. Acesso em 10/08/2016.

BOTO, C. O debate político no Brasil dos anos 30: raça e pedagogia na mística da nacionalidade

Revista Teias, Rio de Janeiro, v. 11, n. 23, p. 63-82, set./dez. 2010. Disponível em: $<$ http://www.e-publicacoes.uerj.br/index.php/revistateias/article/view/24130/17108>. Acesso em: 10 ago. 2016.

CAMARA, S.; COCKELL, M. O intelectual educador Manoel Bomfim e a interpretação do Brasil e da América Latina. Revista HISTEDBR On-Line, Campinas, n. 44, p. 293307, dez. 2011. Disponível em: <http://www.histedbr.fe.unicamp.br/revista/edicoes/44/ art19_44.pdf>. Acesso em: 10 ago. 2016.

CAVADAS, B. F. B. P. O corpo diferente: representações das raças humanas nos manuais escolares de Zoologia. Revista História da Educação (Online), Porto Alegre, v. 17, n. 39, p. 189-212, jan./abr. 2013. Disponível em: <http://www.redalyc.org/ pdf/3216/321627378011.pdf>. Acesso em: 10 ago. 2016.

CRESSONI, F. E. Educando pela palavra: a pedagogia da escravidão nos sermões de Antônio Vieira. Revista Comunicações, Piracicaba, Ano 17, n. 1, p. 55-69, jan./jun. 2010. Disponível em: <https://www.metodista.br/revistas/revistas-unimep/index.php/ comunicacoes/article/view/164/452>. Acesso em: 10 ago. 2016.

DOMINGOS, L. T. A rota oriental da escravidão, a complexa origem das identidades: o caso de Moçambique. Revista da ABPN, Rio de Janeiro, v. 3, n. 6, p. 7-16, nov. 2011/ 
fev. 2012. Disponível em: <http://www.abpn.org.br/Revista/index.php/edicoes/article/ view/146/144>. Acesso em: 10 ago. 2016.

FOE, N. África em diálogo, África em autoquestionamento: universalismo ou provincialismo? "Acomodação de Atlanta" ou iniciativa histórica? Educar em Revista [online], Curitiba, n. 47, p. 175-228, 2013. Disponível em: <http://www.scielo.br/scielo. php?pid=S0104-40602013000100011\&script=sci_abstract\&tlng=pt $>$. Acesso em: 10 ago. 2016.

FONSECA, M. V. A. População negra e civilização: uma análise a partir do estabelecimento da obrigatoriedade escolar em Minas Gerais (1830-1850). Educação em Revista, Belo Horizonte, v. 25, n. 2, p. 43-72, ago. 2009a. Disponível em: <www.scielo.br/pdf/ edur/v25n2/03.pdf>. Acesso em: 10 ago. 2016.

FONSECA M. V. A. Apontamentos em relações às formas de tratamento dos negros pela história da educação. Revista História da Educação, Pelotas, v. 13, n. 28, p. 29-59, maio/ago. 2009b. Disponível em: <http://www.repositorio.ufop.br/bitstream/123456789/4873/1/ARTIGO_ApontamentosRela\%C3\%A7\%C3\%A3oFormas. pdf>. Acesso em: 10 ago. 2016.

FONSECA M. V.A. Educação da Criança Escrava nos Quadros da Escravidão do Escritor Joaquim Manoel de Macedo. Revista Educação e Realidade, Porto Alegre, v. 36, n.1, p. 231-251, jan./abr. 2011. Disponível em: <http://seer.ufrgs.br/educacaoerealidade/article/ viewFile/9483/19844>. Acesso em: 10 ago. 2016.

LORENZ, K. M. A higiene escolar e a eugenia: o papel da educação física na regeneração da "raça brasileira". Revista HISTEDBR On-Line, Campinas, n. 35, p. 19-28, set. 2009. Disponível em: <http://www.histedbr.fe.unicamp.br/revista/edicoes/35/art02_35.pdf>. Acesso em: 10 ago. 2016.

LUZ, I. M. da. Alfabetização e escolarização de trabalhadores negros no Recife oitocentista: perfis e possibilidades. Revista Brasileira de História da Educação, Campinas, v. 13, n. 1(31), p. 69-93, jan./abr. 2013. Disponível em: <http://www.rbhe.sbhe.org.br/ index.php/rbhe/article/viewFile/350/348>. Acesso em: 10 ago. 2016.

MARQUES, J. P. A Invisibilidade do Negro na História do Ceará e os desafios da Lei $n^{\circ}$ 10.639/2003. Poiésis - Unisul, Tubarão, v. 7, n. 12, p. 347-366, jun./dez. 2013. Disponível em: <http://www.portaldeperiodicos.unisul.br/index.php/Poiesis/article/ view/1830/1313>. Acesso em: 10 ago. 2016.

MIRANDA, M. D. da S.; SÁ, E. F. de. Trabalho e escolarização: o universo das crianças negras em Cuiabá. Revista Educativa, Goiânia, v. 14, n. 2, p. 297-312, jul./dez. 2011. Disponível em: <http://seer.ucg.br/index.php/educativa/article/view/1966/1437>. Acesso em: 10 ago. 2016.

MÜLLER, M. L. R. O registro da cor em requerimentos para concursos de professores. Revista Perspectiva, Florianópolis, v. 28, n. 1, 37-62, jan./jun. 2010. Disponível em: <https://periodicos.ufsc.br/index.php/perspectiva/article/view/2175-795X.2010v28n1p37/17840>. Acesso em: 10 ago. 2016. 
PEREIRA, L. R. B. Cultura e Afrodescendëncia: organizações negras e suas estratégias educacionais em Porto Alegre (1872-2002). Reflexão e Ação (UNISC. Impr.), Santa Cruz do Sul, v. 18, p. 77-99, 2010. Disponível em: <https://online.unisc.br/seer/index.php/ reflex/article/viewFile/1338/1056>. Acesso em: 10 ago. 2016.

PINA, M. C. D. Nação e identidade nacional no livro didático de história: a abordagem de Borges dos Reis na Bahia republicana. Revista HISTEDBR On-line, Campinas, número especial, p. 145-163, maio 2010. Disponível em: <http://www.histedbr.fe.unicamp.br/ revista/edicoes/37e/art10_37e.pdf $>$. Acesso em: 10 ago. 2016.

PINTO, S. M. R. A Construção da África: uma reflexão sobre origem e identidade no continente. Revista Eletrônica Acolhendo a Alfabetização nos Países de Língua Portuguesa, São Paulo, ano 2, n. 3, 2007. Disponível em: <http://www.redalyc.org/pdf/879/87920318. pdf>. Acesso em: 10 ago. 2016.

RENK, V. E. O estado e as políticas de branqueamento da população nas escolas, nas primeiras décadas do século XX, no Paraná. Revista Acta Scientiarum, Maringá, v. 36, n. 2, p 223-231, jul./dez. 2014. Disponível em: <http://www.redalyc.org/ pdf/3033/303331286006.pdf>. Acesso em: 10 ago. 2016.

SÁ, N. P.; CRUZ, P. D. R. da. Racismo e instrução pública primária mato-grossense na transição do século XIX para o XX. Revista da Educação Pública, Cuiabá, v. 17, n. 34, p. 285-298, maio/ago. 2008. Disponível em: <http://132.248.9.34/hevila/Revistadeeducacaopublica/2008/no34/5.pdf>. Acesso em: 10 ago. 2016.

SALVADORI, M. A. B. Clubes negros, associativismo e História da Educação. Revista Educação e Fronteiras On-Line, Dourados, v.3, n.9, p. 94-107, maio/ago. 2013. Disponível em: <http://ojs.ws.ufgd.edu.br/index.php?journal=educacao\&page=article\&o $\mathrm{p}=$ view\&path\%5B\%5D=3579\&path\%5B\%5D=pdf_190>. Acesso em: 10 ago. 2016.

SANTOS, N.; CAPRANO, A. M.; LISE, R. S. Racismo e a derrota que não foi esquecida: uma análise dos discursos de Mário Filho e da imprensa escrita acerca da final da Copa do Mundo de 1950. Revista Movimento, Porto Alegre, v. 16, n. 4, p. 191-208, out./dez. 2010. Disponível em: < http://seer.ufrgs.br/index.php/Movimento/article/view/15923/10851>. Acesso em: 10 ago. 2016.

SILVA, A. R. S. da; SILVA, R. S. da S. A História do negro na Educação: entre fatos, ações e desafios. Revista da FAEEBA - Educação e Contemporaneidade, Salvador, v. 14, n. 24, p. 193-204, jul./dez. 2005. Disponível em: < http://www.uneb.br/revistadafaeeba/ files/2011/05/numero24.pdf>. Acesso em: 10 ago. 2016.

SOUZA, M. L. G. de. Representações do negro através das iconografias humorísticas: a sátira e a ironia como tática usada para desvelar no cotidiano escolar. Revista Temas em Educação, João Pessoa, v. 22, n. 1, p. 7-93, jan./jun. 2013. Disponível em: $<$ http://periodicos.ufpb.br/index.php/rteo/article/viewFile/17536/10058>. Acesso em: 10 ago. 2016.

Texto recebido em 30 de dezembro de 2017.

Texto aprovado em 31 de dezembro de 2017. 